\title{
Obesity and Acute Pancreatitis
}

\author{
Davor Štimac and Neven Franjić \\ Division of Gastroenterology, Department of Internal Medicine, \\ University Hospital Rijeka, Rijeka, \\ Croatia
}

\section{Introduction}

Evidence accumulated for the past two decades leads to the conclusion that obesity enhances the development of acute pancreatitis and worsens its clinical course. Is this true? We will try to give an answer to this issue by presenting the scientific data accumulated thus far.

"Obesity is a medical condition in which excess body fat has accumulated to the extent that it may have an adverse effect on health, leading to reduced life expectancy and/or increased health problems." (World Health Organization, 2000) The main problem with obesity is determining the best (and easiest) way to measure it. According to the definition, one should calculate the total amount of body fat a person has and deduct the "normal" amount of fat from it. Several methods have been developed, each with its strengths and weaknesses. (Kamel et al, 2000; Browning et al, 2011)

Body mass index or BMI is the basic method used to determine obesity. It is a measure obtained by dividing the patient's weight (in kilograms) with the square of his/her height (in meters); obesity is defined as BMI $>30 \mathrm{~kg} / \mathrm{m}^{2}$. The method is based on the presumption that a person's excess weight predominantly consists of fat. The advantage of this method is its application simplicity, namely the lack of complicated procedures needed to determine it as well as the fact that it has been globally accepted. The disadvantages are the consequences of the above mentioned presumption namely that a person's excess weight predominantly consists of fat as well as the lack of body composition in the equation: a person who gains weight due to a component other than fat will have a falsely increased BMI, e.g. athletes have muscle hypertrophy; patients with ascites (liver cirrhosis) and peripheral edema (renal failure, heart failure) accumulate water, etc.

Other methods used to determine obesity measure the amount of subcutaneous fat tissue. These methods are based on the fact that the amount of subcutaneous fat tissue correlates well with the amount of excess fat tissue. The methods include the measurement of skin fold thickness, waist diameter and waist-to-hip ratio. As is the case for BMI, these methods are simple, requiring only a meter or a simple measuring instrument and the results are easily interpreted. The limiting factor for these methods is the presence of edema in the investigated areas (liver cirrhosis, heart and kidney diseases).

The method that is not affected by the presence of excess water is dual-energy X-ray absorptiometry (DEXA). It is used to measure body composition based on the difference in the absorption of X-rays in different types of tissues (bone, fat, muscle, water). Compared to 
other methods, DEXA is rather expensive, requires radiological equipment and a radiology specialist to interpret the results; also, it uses radiation (X-rays), which makes it potentially harmful for the patients.

After two decades of tedious work in finding the best method for estimating the amount of body fat in acute pancreatitis, scientists offer no clear answers. Although some data suggest that waist diameter and waist-to-hip ratio have the best correlation with the occurrence of complications in acute pancreatitis, BMI is still widely used as the standard procedure. The following sections offer a detailed insight into the best methods for estimating the amount of body fat in acute pancreatitis.

\section{Epidemiology, etiology and pathogenesis}

\subsection{Epidemiology and etiology}

The epidemiology of acute pancreatitis indicates that the incidence of acute pancreatitis during the last decades has been increasing. (Satoh et al, 2011) Although definitive data are not available, the authors suspect that the main reasons for this are linked to the rise of the underlying causes of pancreatitis - increased alcohol consumption and gallstones. Each cause is responsible for approximately $40 \%$ of cases of acute pancreatitis. (Lowenfels et al, 2009; Spanier et al, 2008; Goldacre \& Roberts, 2004)

Whether obesity has direct consequence on the increased incidence of acute pancreatitis is not clear. Only few epidemiological studies have tried to establish a direct link between obesity and the onset of acute pancreatitis, but the studies' findings are contradictory. (Blomgren et al, 2002; Lowenfels et al, 2005, 2009) The main problem with this theory is the fact that obesity is a well-known risk factor for biliary calculi and consequently for acute biliary pancreatitis. Therefore, it is hard to determine whether or not obesity has a direct impact on the onset of acute pancreatitis.

Another factor taken into consideration when analyzing obesity's effect on the onset of acute pancreatitis is weight distribution. Analyses show that there is no difference in the weight distribution of patients suffering acute pancreatitis and the general population. The reason for this lies in the fact that while patients with biliary pancreatitis tend to be overweight (as obesity is a risk factor for biliary stones), patients suffering alcoholic pancreatitis tend to be lean or even malnourished.

\subsection{Pathogenesis}

The increased interest in obesity is the consequence of the epidemiological boom of obese people and children in post-industrial societies. Since obesity is linked to acute pancreatitis, there have been many speculations about the pathogenetic links between the two. (Bastard et al, 2006; Fuentes et al, 2010; Frossard et al, 2009)

Ever since the discovery of adipokines, hormones synthesized and excreted by the cells residing in the adipose tissue, the endocrine function of adipose tissue has become even more intricate. Adipokines once included only biologically-active substances secreted by the adipocytes, but today they refer to all biologically-active substances produced by the adipose tissue.

The principal anti-inflammatory substance secreted by the adipocytes is adiponectin. It is a 30-kDa protein with plasma levels ranging from 5 to $30 \mathrm{mg} / \mathrm{L}$ in lean subjects. Adiponectin has many potentially beneficial effects in acute pancreatitis (Zyromski et al, 2008): it enhances insulin-sensitivity (Yamauchi et al, 2002), modulates endothelial adhesion 
molecules (Ouchi et al, 1999), alters macrophage and lymphocyte action (Ouchi et al, 2001; Wolf et al, 2004) and modulates the balance of cytokines in favor of anti-inflammatory cytokines (Ouchi et al, 2000; Huang et al, 2008; Masaki et al, 2004)

Leptin, a pro-inflammatory adipokine synthesized in the adipocytes, is on the opposite side of the spectrum. Leptin acts pro-inflammatory by regulating cytokine production in favor of pro-inflammatory cytokines (Fantuzzi \& Faggioni, 2000; Santosa et al, 2007) and by enhancing leukocyte activity (Loffreda et al, 1998; Lord et al, 1998). On the other hand, a study performed by Matyjek et al. showed an inhibitory effect of leptin on cholecystokininrelated secretion of pancreatic enzymes. (Matyjek et al, 2003)

Resistin is another adipokine, a $12.5 \mathrm{kDa}$ protein produced mainly by monocytes and macrophages. Its effects include increased insulin resistance and dyslipidemia. (Steppan et al, 2001; Trayhurn \& Wood, 2004)

According to modern conceptions, obese people are in a state of chronic inflammation. Studies have shown that excess adipose tissue generates more leptin and resistin, and less adiponectin. This, in turn, leads to the prevalence of pro-inflammatory over antiinflammatory cytokines, resulting in a state of constant inflammation of the adipose tissue. (Frossard et al, 2009) The residing macrophages are affected as well. Normal fat tissue contains a balance of the so-called M1 or pro-inflammatory macrophages and the so-called M2 or anti-inflammatory macrophages. In obesity, the scale is tipped in favor of M1 macrophages; the net-result is a constant over-production of various pro-inflammatory cytokines, like interleukin-1 (IL-1), interleukin-6 (IL-6) or tumor necrosis factor-alpha (TNFalpha).

The pro-inflammatory effect of excess adipose tissue varies throughout the body and depends on the place where excess fat is stored. The worst place it can be stored is the intraabdominal compartment; visceral adipose tissue is metabolically the most active adipose tissue and the most "pro-inflammatory oriented". (Clement \& Langin, 2007) Because the veins of the visceral adipose tissue drain into the portal system, the hormonal products and free-fatty acids (FFAs) produced by the visceral adipose tissue directly influence the liver and cause central insulin resistance. This is the pathogenetic pathway by which the central obesity causes cardiovascular diseases as well as diabetes. Free-fatty acids, however, act through toll-like receptors (TLRs) inducing an inflammatory response in macrophages, adipocytes and muscle-cells.

The central dogma of the acute pancreatitis etiopathogenesis is the uncontrolled intrapancreatic conversion of trypsinogen into trypsin. In theory, it is rather easy to imagine how an altered pro-inflammatory cytokine milieu could trigger the activation of trypsinogen, leading to the onset of acute pancreatitis. Clinical data are, however, inconclusive. Therefore, we must be overlooking some important factors in the development of acute pancreatitis.

\section{Clinical course}

The clinical course of acute pancreatitis follows two discrete patterns. It can be a mild disease, resulting in edematous interstitial inflammation of the pancreas and resolving without consequences within a week. On the other hand, it can be a severe, debilitating disease, manifested by pancreatic and peripancreatic necroses and resulting, in turn, in local and systemic complications. Can obesity influence the course of the disease? 
Obesity is a chronic subclinical inflammatory disorder that, in theory, can influence the clinical course of acute pancreatitis. There is evidence that obese patients have elevated levels of pro-inflammatory cytokines circulating in their blood. (Clement \& Langin, 2007) This, in turn, can affect the course of the disease by enhancing inflammation and increasing the chance of necrosis.

The second way excess fat can influence the course of acute pancreatitis is by increasing the risk of pancreatic infection and the severity of inflammation. In the course of acute pancreatitis, the inflammation affects peri-pancreatic adipose tissue as well. The risk of complications is proportional to the amount of excess fat tissue in the peri-pancreatic area, which is a component of the visceral adipose tissue. (Frossard et al, 2009) On the other hand, excess peripancreatic fat could be a protective factor by separating the pancreatic tissue from the retroperitoneal structures thus localizing the necrotizing process.

The third, and often neglected problem in obese patients with acute pancreatitis is (chronic) insulin resistance. It is a common denominator of obesity and carries the burden of type II diabetes development. Insulin resistance is a system-wide problem which affects both the vasculature and the immune system and can give rise to microcirculatory problems which can cause pancreatic ischemia. (Mentula et al, 2007) Insulin resistance (acute) is actually a physiological reaction accompanying acute immune reactions and stress. The body needs energy and nutrients, i.e. glucose, amino-acids and free-fatty acids. In order to meet its needs, the body must inhibit nutrient uptake and reverse the process: cells which are not needed degrade its proteins, carbohydrates and lipids in order to produce the abovementioned nutrients. That way the body fuels up the immune reactions and makes healing possible. When the healing (reconvalescence period) is complete, the body lowers insulin resistance to normal levels. The problem is when this state persists for a long time, as in the case of obesity. As a result, the body is not able to adequately react to the traumatic experience (acute pancreatitis) and prolonged healing follows.

Although all the proposed mechanisms seem logical, clinical data have failed us once again. Some of the studies do show a statistical significance in the outcomes of obese and nonobese pancreatitis patients; however, other studies do not confirm these findings. Even in some studies, which support the idea that obese patients tend to have a more complicated course of acute pancreatitis, the confidence interval is rather wide, indicating possibly biased data. A possible explanation is that the measure of obesity used in the studies is not the real measure of obesity.

Unfortunately, as with many other topics covering acute pancreatitis, we still await an unequivocal conclusion.

\section{Obesity measures}

Various obesity measurements are used in everyday practice. However, modern tendencies are to simplify disease management and at the same time be cost-effective. Complex measurements are performed in high-volume hospitals and university hospitals; smaller hospitals employ simplified methods more suited to smaller budgets. Body-mass index (BMI) and waist diameter are the methods which fulfill the mentioned criteria.

\subsection{BMI}

As mentioned before, BMI is calculated by dividing the patient's weight (in kilograms) with the square of his/her height (in meters). Patients with BMI above $25 \mathrm{~kg} / \mathrm{m}^{2}$ are defined as 
overweight; above $30 \mathrm{~kg} / \mathrm{m}^{2}$ are obese. These are, again, divided into three subcategories: type I obesity ranging from 30 to $35 \mathrm{~kg} / \mathrm{m}^{2}$, type II or severe obesity ranging from 35 to 40 $\mathrm{kg} / \mathrm{m}^{2}$ and type III or morbid obesity with BMI levels above $40 \mathrm{~kg} / \mathrm{m}^{2}$.

Several studies have tried to substantiate the idea that obesity predisposes a person for the development of acute pancreatitis. Suazo-Barájona et al. in 1998 found a significant difference in the occurrence of severe acute pancreatitis between patients with BMI $\geq 25$ $\mathrm{kg} / \mathrm{m}^{2}$ (overweight and obese), and those with BMI $<25 \mathrm{~kg} / \mathrm{m}^{2}$ (lean). The differentiation of the overweight and the obese into separate groups is performed only graphically. The graph shows a tendency of patients with higher BMI to develop severe acute pancreatitis more often. (Suazo-Barájona et al, 1998) Johnson et al. modified the APACHE II score by adding BMI into the scoring system. A value of 1 or 2 is added to the "classic" APACHE score depending on the value of BMI. (Johnson et al, 2004) The study, along with a study from Papachristou et al two years later, showed a positive correlation between the BMI and the disease' severity, though in the second study the APACHE-O score did not perform better than the original APACHE II score. (Papachristou et al, 2006) In 2006, a meta-analysis was performed by Martinez et al in order to determine the effect of BMI on the occurrence of local complications, systemic complications and mortality. The meta-analysis included 739 patients and clearly showed an increased incidence of local and systemic complications, as well as increased mortality. However, with respect to mortality, the odds ratio (OR) for the obese patients was 2.1 , but with a 95\% confidence interval (CI) ranging from 1.0 to 4.8 (figure 1). This implies an increased mortality risk in obese patients suffering acute pancreatitis, but it should be taken into careful consideration. (Martinez et al, 2006) In the period after 2006, several studies negating the effect of BMI on disease severity have been published. (Mentula et al, 2007; Stimac et al, 2007) The last meta-analysis published in 2011 (Wang et al, 2011) included 8 studies with 939 patients. The meta-analysis showed that the incidence rates of severe acute pancreatitis, local complications and mortality were all increased in overweight patients (OR 2.48, 2.58 and 3.81, respectively). The last metaanalysis did not show correlation between BMI and systemic complications, though.

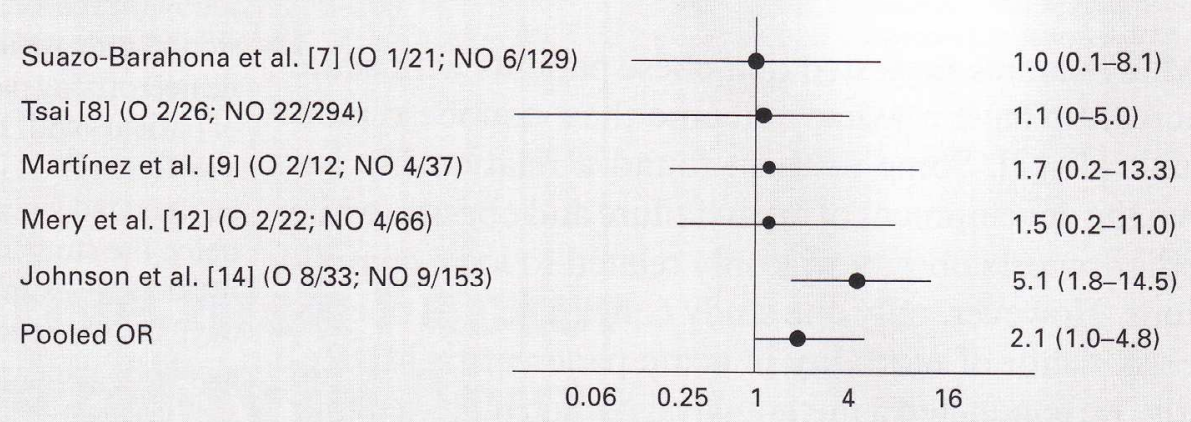

Fig. 1. The results of the meta-analysis performed by Martinez et al. (Martinez et al, 2006) The influence of obesity on the mortality in patients suffering acute pancreatitis is shown in the forest plot with a calculated pooled odds ratio (OR). $\mathrm{O}=$ Obese; $\mathrm{NO}=$ Nonobese 


\subsection{Waist diameter and waist-hip ratio}

Waist diameter or circumference is the measurement of the shortest abdominal distance, halfway between the lower rib margin and the iliac crest. Men with a waist diameter $<94$ $\mathrm{cm}, 94-101.9 \mathrm{~cm}$ and $\geq 102 \mathrm{~cm}$ are defined as lean, overweight and obese. Similarly, in women the values are $<80 \mathrm{~cm}, 80-87.9 \mathrm{~cm}$ and $\geq 88 \mathrm{~cm}$, respectively.

Waist-to-hip or waist-hip ratio is calculated by dividing the waist diameter with the hip diameter. The hip diameter is acquired by measuring the abdominal diameter at the level of the hips. Again, the distribution is $<0.90,0.90-0.99$ and $\geq 1.00$ for lean, overweight and obese men. In women, the cut-off values are 0.80 and $0.85(<0.80,0.80-0.84$ and $\geq 0.85)$.

The mentioned ranges are reference ranges defined for the European population. Differences exist among different populations. The American societies define the ranges somewhat higher, while the Asian societies tend to lower the ranges, mirroring the normal distribution of waist diameter and waist-hip ratio in the respective populations.

The idea of analyzing waist diameter and waist-hip ratio as a predictive factor in acute pancreatitis has emerged as early as in the 90's, but only several studies have been performed thus far. In 1999, Martinez et al. showed that waist diameter was greater in patients with severe acute pancreatitis than in patients with the mild form. (Martínez et al, 1999) A second study in which Torgerson et al. tried to determine the impact of obesity on the occurrence of gallstones, gallbladder disease and pancreatitis was limited by the small number of patients suffering acute pancreatitis. (Torgerson et al, 2003) The latest study published in 2010 by Duarte-Rojo et al. showed that waist diameter, waist-hip ratio and waist-thigh ratio all correlated well with the severity of acute pancreatitis. The study also showed that waist diameter correlated best with the subcutaneous abdominal fat, while the waist-hip ratio showed a similar correlation with intra-abdominal fat. (Duarte-Rojo et al, 2010)

Fluid sequestration in the retroperitoneal compartment affects both the BMI and the abdominal obesity measures. With fluid retention, the measures become inaccurate in assessing obesity as they tend to overestimate the amount of body fat, and become more accurate in predicting disease severity (the more the fluid is sequestered the more severe the course of the disease). That is perhaps the reason why some studies have shown a good correlation between obesity measures and disease severity, while others did not. In the case of fluid retention, abdominal measures should theoretically have a greater prognostic significance than BMI; one should note that this does not imply obesity as well. (Beger \& Rau, 2007)

Whether BMI or abdominal measures are the best disease severity predictors still remains to be seen. Studies comparing the two are needed.

\section{Treatment differences}

Current approach to acute pancreatitis management depends mostly on the course the disease will follow. Specific therapy for acute pancreatitis does not exist, as medications which could impede the development of the disease or change its course have not been found yet. Therefore, the only therapy is symptomatic and depends on the patient's status. In mild edematous pancreatitis, fluid resuscitation and oral food intake prohibition will enhance the patient's recovery. Even the lack of therapy would yield a similar result, as in this case the disease is self-limited. For this type of pancreatitis there are no differences in the management of obese and non-obese patients. 
Severe necrotizing pancreatitis is the therapeutic nightmare for every gastroenterologist and intensivist. In the acute phase of the disease (within 7 days from onset), the main problem is organ failure. Obese patients tend to have more local and systemic complications, and respiratory failure is among the more common ones. Therefore, in the management of obese patients, aggressive fluid resuscitation with a special concern for respiratory function is of utmost importance. Since obesity carries the risk of type II diabetes, and glucose intolerance is rather often found in the acute phase of acute pancreatitis, insulin is usually added to glucose or Ringer solutions in order to maintain glucose levels under $10 \mathrm{mmol} / \mathrm{L} \mathrm{(180}$ mg/dL). (Di Carlo et al, 1981; Pisters \& Ranson, 1992)

The main problem in the subacute phase of acute pancreatitis is the elevated risk of infection. Insulin resistance can impede the normal function of the immune system and lead to serious infections. (Turina et al, 2005) Therefore, antibiotic prophylaxis should be given in order to prevent this setting from taking place.

Since the predilection of obese patients for local and systemic complications is still under revision, the measures are opinion-based and not substantiated with evidence from RCTs. However, common sense dictates us to monitor such patients more closely in order to try to prevent the worst from happening.

\section{Nutritional support}

As obesity is (usually) a nutritional disorder, nutritional support in acute pancreatitis is separated from other therapeutic interventions. (Ionnanidis et al, 2008)

Due to the lack of specific therapy, the modern mainstay of therapy of acute pancreatitis is "pancreatic rest". (Cassim \& Allardyce, 1974) This means that the pancreas should be stimulated as little as possible in order to enable it to contain the inflammation and give it time to heal itself. Again, the treatment approach for patients with mild pancreatitis differs from those suffering severe pancreatitis.

In mild pancreatitis food is withheld for several days, after which the patient is given oral food, first in the form of water and tea, followed by the so-called "pancreatic" diet (food rich in carbohydrates and scarce in fats). If the patient cannot tolerate oral intake, enteral or even parenteral feeding should be administered. Obese patients are treated the same way.

In severe pancreatitis, the approach is more invasive. Patients are fed enterally through a naso-jejunal tube. If they cannot tolerate enteral feeding, or enteral feeding is inadequate, parenteral feeding is added. Obese patients should be fed according to ideal weight and not the actual one. The target energy requirements include $25-35 \mathrm{kcal} / \mathrm{kg}$ of ideal body weight, with 1.2-1.5 g of nitrogen per $\mathrm{kg}$ of ideal body weight. (Choban \& Dickerson, 2005; Elamin, 2005) One should note that this means that obese patients are 'permissively underfed'. In their case, weight reduction can have beneficial effects on insulin resistance and the overall status of the patient. (Martindale et al, 2009)

Plasma glucose levels should be monitored at least twice a day, more intensively in case of offset values. High glucose values (above $10.0 \mathrm{mmol} / \mathrm{L}$ ) should be corrected with subcutaneous administration of insulin.

\section{Treatment}

The treatment of acute pancreatitis in obese patients is summarized in table 1 . 
Mild pancreatitis

food restriction

(depending on clinical severity)

fluid resuscitation

(depending on laboratory values)

\section{Severe pancreatitis}

enteral nutrition, parenteral (amount calculated according to ideal weight)

if needed

aggressive fluid

(up to 4-6 L daily, depending on the state of the

resuscitation cardiovascular system)

insulin according to plasma glucose levels

oxygen therapy depending on oxygen saturation

antibiotic prophylaxis

(carbapenems, ciprofloxacin, metronidazole)

Table 1. Therapeutic approach in obese patients with acute pancreatitis

\section{Conclusion}

In the end, we will talk about the future and what it holds for obese patients suffering from acute pancreatitis.

Scientists and clinical practitioners are presently searching for new and better ways to help patients suffering from acute pancreatitis and are exploring ways to overcome and combat the disease.

In the field of diagnostics, most researches are battling with the issue of identifying prognostic factors for severe acute pancreatitis. The goal is to find a diagnostic tool that could predict and determine the course of the disease at admission. This is especially important for obese patients, as they tend to have a more complicated disease.

In the field of therapy, most researches are concentrated on finding a medication that could alter the course of the disease. A number of substances have been investigated in order to achieve this, but to no avail. Specific therapy would reduce the number of complications and mortality to ppm levels.

Finally, scientists are trying to find the best possible methods and interventions to treat acute pancreatitis complications. Again, it is an issue of utmost importance for the obese, as interventions are more difficult in these patients and carry out a greater risk of procedural complications and mortality.

Although the mentioned investigations are related to acute pancreatitis, there are a number of options available for implementing effective interventions for treating obesity. Will these obesity treatment procedures have positive effects on and will they become a part of acute pancreatitis treatment procedures, only time will show!

\section{References}

Bastard JP, Maachi M, Lagathu C, Kim MJ, Caron M, Vidal H, Capeau J, Feve B. Recent advances in the relationship between obesity, inflammation, and insulin resistance. Eur Cytokine Netw. 2006 Mar; 17(1): 4-12. 
Beger HG \& Rau BM. Severe acute pancreatitis: Clinical course and management. World J Gastroenterol. 2007 Oct 14; 13(38): 5043-51. Review.

Blomgren KB, Sundström A, Steineck G \& Wiholm BE. Obesity and treatment of diabetes with glyburide may both be risk factors for acute pancreatitis. Diabetes Care. 2002 Feb; 25(2): 298-302.

Browning LM, Mugridge O, Dixon AK, Aitken SW, Prentice AM \& Jebb SA. Measuring abdominal adipose tissue: comparison of simpler methods with MRI. Obes Facts. 2011; 4(1): 9-15.

Cassim MM \& Allardyce DB. Pancreatic secretion in response to jejunal feeding of elemental diet. Ann Surg. 1974 Aug; 180(2): 228-31.

Choban PS \& Dickerson RN. Morbid obesity and nutrition support: is bigger different? Nutr Clin Pract. 2005 Aug;20(4):480-7. Review.

Clement K \& Langin D. Regulation of inflammation-related genes in human adipose tissue. J Intern Med. 2007 Oct; 262(4): 422-30. Review.

Di Carlo V, Nespoli A, Chiesa R, Staudacher C, Cristallo M, Bevilacqua G \& Staudacher V. Hemodynamic and metabolic impairment in acute pancreatitis. World J Surg. 1981 May; 5(3): 329-39.

Duarte-Rojo A, Sosa-Lozano LA, Saúl A, Herrera-Cáceres JO, Hernández-Cárdenas C, Vázquez-Lamadrid J \& Robles-Díaz G. Methods for measuring abdominal obesity in the prediction of severe acute pancreatitis, and their correlation with abdominal fat areas assessed by computed tomography. Aliment Pharmacol Ther. 2010 Jul; 32(2): 244-53.

Elamin EM. Nutritional care of the obese intensive care unit patient. Curr Opin Crit Care. 2005 Aug;11(4):300-3. Review.

Fantuzzi G \& Faggioni R. Leptin in the regulation of immunity, inflammation, and hematopoiesis. J Leukoc Biol. 2000 Oct; 68(4): 437-46.

Frossard JL, Lescuyer P \& Pastor CM. Experimental evidence of obesity as a risk factor for severe acute pancreatitis. World J Gastroenterol. 2009 Nov 14; 15(42): 5260-5.

Fuentes L, Roszer T \& Ricote M. Inflammatory mediators and insulin resistance in obesity: role of nuclear receptor signaling in macrophages. Mediators Inflamm. 2010; 2010:219583. Epub 2010 May 20.

Goldacre MJ, Roberts SE. Hospital admission for acute pancreatitis in an English population, 1963-98: database study of incidence and mortality. BMJ. 2004 Jun 19; 328(7454): 1466-9.

Huang H, Park PH, McMullen MR \& Nagy LE. Mechanisms for the anti-inflammatory effects of adiponectin in macrophages. J Gastroenterol Hepatol. 2008 Mar; 23 Suppl 1: S50-3. Review.

Ioannidis O, Lavrentieva A, Botsios D. Nutrition support in acute pancreatitis. JOP. 2008 Jul 10; 9(4): 375-90. Review.

Johnson CD, Toh SK \& Campbell MJ. Combination of APACHE-II score and an obesity score (APACHE-O) for the prediction of severe acute pancreatitis. Pancreatology. 2004; 4(1): 1-6. Epub 2004 Feb 24.

Kamel EG, McNeill G \& Van Wijk MC. Usefulness of anthropometry and DXA in predicting intra-abdominal fat in obese men and women. Obes Res. 2000 Jan; 8(1): 36-42. 
Loffreda S, Yang SQ, Lin HZ, Karp CL, Brengman ML, Wang DJ, Klein AS, Bulkley GB, Bao C, Noble PW, Lane MD \& Diehl AM. Leptin regulates proinflammatory immune responses. FASEB J. 1998 Jan; 12(1): 57-65.

Lord GM, Matarese G, Howard JK, Baker RJ, Bloom SR \& Lechler RI. Leptin modulates the T-cell immune response and reverses starvation-induced immunosuppression. Nature. 1998 Aug 27; 394(6696): 897-901.

Lowenfels AB, Sullivan T, Fiorianti J \& Maisonneuve P. The epidemiology and impact of pancreatic diseases in the United States. Curr Gastroenterol Rep. 2005 May; 7(2): 90-5.

Lowenfels AB, Maisonneuve P \& Sullivan T. The changing character of acute pancreatitis: epidemiology, etiology, and prognosis. Curr Gastroenterol Rep. 2009 Apr; 11(2): 97103.

Martindale RG, McClave SA, Vanek VW, McCarthy M, Roberts P, Taylor B, Ochoa JB, Napolitano L, Cresci G; American College of Critical Care Medicine; A.S.P.E.N. Board of Directors. Guidelines for the provision and assessment of nutrition support therapy in the adult critically ill patient: Society of Critical Care Medicine and American Society for Parenteral and Enteral Nutrition: Executive Summary. Crit Care Med. 2009 May; 37(5): 1757-61. Review.

Martínez J, Sánchez-Payá J, Palazón JM, Aparicio JR, Picó A \& Pérez-Mateo M. Obesity: a prognostic factor of severity in acute pancreatitis. Pancreas. 1999 Jul; 19(1): 15-20.

Martínez J, Johnson CD, Sánchez-Payá J, de Madaria E, Robles-Díaz G \& Pérez-Mateo M. Obesity is a definitive risk factor of severity and mortality in acute pancreatitis: an updated meta-analysis. Pancreatology 2006; 6: 206-9.

Masaki T, Chiba S, Tatsukawa H, Yasuda T, Noguchi H, Seike M \& Yoshimatsu H. Adiponectin protects LPS-induced liver injury through modulation of TNF-alpha in KK-Ay obese mice. Hepatology. 2004 Jul; 40(1): 177-84.

Matyjek R, Herzig KH, Kato S \& Zabielski R. Exogenous leptin inhibits the secretion of pancreatic juice via a duodenal CCK1-vagal-dependent mechanism in anaesthetized rats. Regul Pept. 2003 Jun 15; 114(1): 15-20.

Mentula P, Kylänpää ML, Kemppainen E, Repo H \& Puolakkainen P. Early inflammatory response in acute pancreatitis is little affected by body mass index. Scand J Gastroenterol 2007 Nov; 42(11): 1362-8.

Ouchi N, Kihara S, Arita Y, Maeda K, Kuriyama H, Okamoto Y, Hotta K, Nishida M, Takahashi M, Nakamura T, Yamashita S, Funahashi T \& Matsuzawa Y. Novel modulator for endothelial adhesion molecules: adipocyte-derived plasma protein adiponectin. Circulation. 1999 Dec 21-28; 100(25): 2473-6.

Ouchi N, Kihara S, Arita Y, Nishida M, Matsuyama A, Okamoto Y, Ishigami M, Kuriyama H, Kishida K, Nishizawa H, Hotta K, Muraguchi M, Ohmoto Y, Yamashita S, Funahashi T \& Matsuzawa Y. Adipocyte-derived plasma protein, adiponectin, suppresses lipid accumulation and class A scavenger receptor expression in human monocyte-derived macrophages. Circulation. 2001 Feb 27; 103(8): 1057-63.

Ouchi N, Kihara S, Arita Y, Okamoto Y, Maeda K, Kuriyama H, Hotta K, Nishida M, Takahashi M, Muraguchi M, Ohmoto Y, Nakamura T, Yamashita S, Funahashi T \& Matsuzawa Y. Adiponectin, an adipocyte-derived plasma protein, inhibits 
endothelial NF-kappaB signaling through a cAMP-dependent pathway. Circulation. 2000 Sep 12; 102(11): 1296-301.

Papachristou GI, Papachristou DJ, Avula H, Slivka A \& Whitcomb DC. Obesity increases the severity of acute pancreatitis: performance of APACHE-O score and correlation with the inflammatory response. Pancreatology. 2006; 6(4): 279-85. Epub 2006 Apr 19 .

Pisters PW \& Ranson JH. Nutritional support for acute pancreatitis. Surg Gynecol Obstet. 1992 Sep; 175(3): 275-84. Review.

Santosa S, Demonty I, Lichtenstein AH, Cianflone K \& Jones PJ. An investigation of hormone and lipid associations after weight loss in women. J Am Coll Nutr. 2007 Jun; 26(3): 250-8.

Satoh K, Shimosegawa T, Masamune A, Hirota M, Kikuta K, Kihara Y, Kuriyama S, Tsuji I, Satoh A, Hamada S \& Research Committee of Intractable Diseases of the Pancreas. Nationwide epidemiological survey of acute pancreatitis in Japan. Pancreas 2011 May; 40(4): 503-7.

Spanier BW, Dijkgraaf MG \& Bruno MJ. Epidemiology, aetiology and outcome of acute and chronic pancreatitis: An update. Best Pract Res Clin Gastroenterol. 2008; 22(1): 45-63.

Steppan CM, Bailey ST, Bhat S, Brown EJ, Banerjee RR, Wright CM, Patel HR, Ahima RS \& Lazar MA. The hormone resistin links obesity to diabetes. Nature. 2001 Jan 18; 409(6818): 307-12.

Štimac D, Krznarić Zrnić I, Radić M \& Žuvić-Butorac M. Outcome of the biliary acute pancreatitis is not associated with body mass index. Pancreas 2007 Jan; 34(1): 165-6.

Suazo-Baráhona J, Carmona-Sánchez R, Robles-Díaz G, Milke-García P, Vargas-Vorácková F, Uscanga-Domínguez L \& Peláez-Luna M. Obesity: a risk factor for severe acute biliary and alcoholic pancreatitis. Am J Gastroenterol. 1998 Aug; 93(8): 1324-8.

Torgerson JS, Lindroos AK, Näslund I \& Peltonen M. Gallstones, gallbladder disease, and pancreatitis: cross-sectional and 2-year data from the Swedish Obese Subjects (SOS) and SOS reference studies. Am J Gastroenterol. 2003 May; 98(5): 1032-41.

Trayhurn P, Wood IS. Adipokines: inflammation and the pleiotropic role of white adipose tissue. Br J Nutr. 2004 Sep; 92(3): 347-55. Review.

Turina M, Fry DE \& Polk HC Jr. Acute hyperglycemia and the innate immune system: clinical, cellular, and molecular aspects. Crit Care Med. 2005 Jul; 33(7): 1624-33. Review.

Wang SQ, Li SJ, Feng QX, Feng XY, Xu L \& Zhao QC. Overweight Is an Additional Prognostic Factor in Acute Pancreatitis: A Meta-Analysis. Pancreatology. 2011 May 17; 11(2): 92-98.

Wolf AM, Wolf D, Rumpold H, Enrich B \& Tilg H. Adiponectin induces the antiinflammatory cytokines IL-10 and IL-1RA in human leukocytes. Biochem Biophys Res Commun. 2004 Oct 15; 323(2): 630-5.

World Health Organization. Obesity: preventing and managing the global epidemic. Report of a WHO Consultation. Geneva, Switzerland: World Health Organization, 2000. (WHO technical report series 894).

Yamauchi T, Kamon J, Minokoshi Y, Ito Y, Waki H, Uchida S, Yamashita S, Noda M, Kita S, Ueki K, Eto K, Akanuma Y, Froguel P, Foufelle F, Ferre P, Carling D, Kimura S, 
Nagai R, Kahn BB \& Kadowaki T. Adiponectin stimulates glucose utilization and fatty-acid oxidation by activating AMP-activated protein kinase. Nat Med. 2002 Nov; 8(11): 1288-95. Epub 2002 Oct 7.

Zyromski NJ, Mathur A, Pitt HA, Lu D, Gripe JT, Walker JJ, Yancey K, Wade TE \& SwartzBasile DA. A murine model of obesity implicates the adipokine milieu in the pathogenesis of severe acute pancreatitis. Am J Physiol Gastrointest Liver Physiol. 2008 Sep; 295(3): G552-8. Epub 2008 Jun 26. 


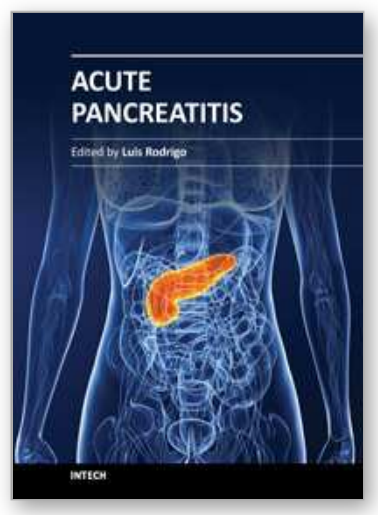

\author{
Acute Pancreatitis \\ Edited by Prof. Luis Rodrigo
}

ISBN 978-953-307-984-4

Hard cover, 300 pages

Publisher InTech

Published online 18, January, 2012

Published in print edition January, 2012

Acute Pancreatitis (AP) in approximately $80 \%$ of cases, occurs as a secondary complication related to gallstone disease and alcohol misuse. However there are several other different causes that produce it such as metabolism, genetics, autoimmunity, post-ERCP, and trauma for example... This disease is commonly associated with the sudden onset of upper abdominal pain that is usually severe enough to warrant the patient seeking urgent medical attention. Overall, $10-25 \%$ of AP episodes are classified as severe. This leads to an associated mortality rate of $7-30 \%$ that has not changed in recent years. Treatment is conservative and generally performed by experienced teams often in ICUs. Although most cases of acute pancreatitis are uncomplicated and resolve spontaneously, the presence of complications has a significant prognostic importance. Necrosis, hemorrhage, and infection convey up to $25 \%, 50 \%$, and $80 \%$ mortality, respectively. Other complications such as pseudocyst formation, pseudo-aneurysm formation, or venous thrombosis, increase morbidity and mortality to a lesser degree. The presence of pancreatic infection must be avoided.

\title{
How to reference
}

In order to correctly reference this scholarly work, feel free to copy and paste the following:

Davor Stimac and Neven Franjić (2012). Obesity and Acute Pancreatitis, Acute Pancreatitis, Prof. Luis Rodrigo (Ed.), ISBN: 978-953-307-984-4, InTech, Available from: http://www.intechopen.com/books/acutepancreatitis/obesity-and-acute-pancreatitis

\section{INTECH}

open science | open minds

\author{
InTech Europe \\ University Campus STeP Ri \\ Slavka Krautzeka 83/A \\ 51000 Rijeka, Croatia \\ Phone: +385 (51) 770447 \\ Fax: +385 (51) 686166 \\ www.intechopen.com
}

\author{
InTech China \\ Unit 405, Office Block, Hotel Equatorial Shanghai \\ No.65, Yan An Road (West), Shanghai, 200040, China \\ 中国上海市延安西路65号上海国际贵都大饭店办公楼 405 单元 \\ Phone: +86-21-62489820 \\ Fax: $+86-21-62489821$
}


(C) 2012 The Author(s). Licensee IntechOpen. This is an open access article distributed under the terms of the Creative Commons Attribution 3.0 License, which permits unrestricted use, distribution, and reproduction in any medium, provided the original work is properly cited. 